\title{
Ego Integrity in the Lives of Older Women: A Follow-Up of Mothers From the Sears, Maccoby, and Levin (1951) Patterns of Child Rearing Study
}

\author{
Jacquelyn Boone James ${ }^{1,3}$ and Nicole Zarrett ${ }^{2}$
}

\begin{abstract}
Ego integrity, Erik Erikson's (E. H. Erikson, 1963) concept of psychological maturity in later life and the pinnacle of 8 stages, has been one of the least studied of all his stage constructs. This paper explores the meaning of ego integrity (as assessed by C. D. Ryff \& S. G. Heincke, 1983 ) in the lives of a sample of older women, by examining the predictors and concomitants of ego integrity (EI), using data from interviews conducted with the same women in 1951 and 1996 and a questionnaire administered in 1996. A 3-step regression model revealed that "identity" assessed in 1951 predicted generativity in 1996; the level of educational attainment and marital status were also significant predictors. In step 2, generativity alone predicted ego integrity, which in turn predicted depression. Ego integrity was associated with higher marital satisfaction in the mothers' lives, both in the past and in the present; it was implicated in better relationships with their adult children, in the mothers' willingness to both give and receive help, and in several dimensions of psychological well-being.
\end{abstract}

KEY WORDS: identity; generativity; ego integrity; older mothers' lives; psychological well-being.

Ego integrity, Erik Erikson's (1963) concept of psychological maturity in later life and the pinnacle of his "eight stages of man," has proven to be one of the most difficult of his concepts to discern. Ego integrity (EI) received the smallest amount of space in Erikson's writing, lacks clear definition by his own admission, and has been questioned as a valid descriptor of the experiences of older people. Even though there has been progress in understanding the various elements of EI (see for example, Erikson, Erikson, \& Kivnick, 1986; Vaillant, 2002; Whitbourne, Zuschlag, Elliot, \& Waterman, 1992) it remains one of the least studied of all of Erikson's stage constructs. We have learned that EI involves getting one's inner life in order,

\footnotetext{
${ }^{1}$ Harvard University, Cambridge, Massachusetts.

${ }^{2}$ University of Michigan, Michigan.

${ }^{3}$ To whom correspondence should be addressed at Murray Research Center, 10 Garden Street, Cambridge, Massachusetts 02138; e-mail: j_james@harvard.edu.
}

but very little is known about how it affects one's outer life, i.e., how one relates to spouse, children, community, and so on. Given the extent to which other elements of Erikson's theoretical model, especially generativity and the social good it inspires (Kotre, 1984; McAdams, 1993, 2000; McAdams \& de St. Aubin, 1992; Peterson \& Duncan, 1999; Slater, 2003), along with attention to "successful aging" and the important adaptive work required for it (Baltes \& Mayer, 1999), we believe that more attention to $\mathrm{EI}$ and its concomitants is needed. This focus is made more worthwhile as later life is prolonged and the elderly population expands.

Few of the studies reviewed here considered EI as the lone focus of study. The purpose of this paper is to explore the meaning of EI, as assessed by a measure developed by Ryff and Heincke (1983), in the lives of a sample of relatively healthy older women. In a study designed to assess multiple aspects of older women's lives, we will examine the predictors and concomitants of EI, using data from interviews 
conducted with the same women in 1951 and 1996 and a questionnaire administered in 1996.

\section{Theoretical Background}

Erik Erikson is one of few theorists who posited a trajectory of development that spans from infancy to old age. Erikson's (1963) theoretical model is also one of the few that embraces the concepts of individual challenges across life that play out in the context of a social and historical milieu, and acknowledges the potential for human possibility and strength. According to the theory, the adult stages are intimacy (affiliation and love), generativity (bringing along the next generation), and EI (assigning order and meaning to the whole of one's life, versus despairwhich flows from the feeling that one's life has been wasted). In Erikson's view, ego integrity is the "fruit of these seven stages" (Erikson, 1963, p. 168).

Ego integrity, according to Erikson (1963), can be seen in individuals who are concerned with issues surrounding aging, with integrating one's life experiences, with making sense of life and death, and in individuals who are preoccupied with the specifics of those tasks. According to the theory, meeting these challenges is important for psychological well-being in later life and for the development of wisdom.

\section{Summary of Research With Eriksonian Theory: Ego Integrity}

A great deal of empirical work has been generated by Erikson's model of development, most of which, until recently, has examined its applicability to younger people and their concern with identity development (Hannah, Domino, Figuero, \& Hendrickson, 1996). In fact many of the scales developed to measure Eriksonian stages assess only one of them. During the last decade, for example, a focus on midlife has spawned rather prolific work on generativity (e.g., MacDermid, Franz, \& De Reus, 1998; McAdams, de St. Aubin, \& Logan, 1993; Peterson \& Stewart, 1993; Stewart, Osborne, \& Helson, 2001). In all of the studies we examined, even in cases where more than one stage is considered, EI is the one most notably left out.

When EI is the focus of study, researchers have used proxies of it e.g., self-esteem or indicators of depression (Nehrke, Bellucci, \& Gabriel, 1978; Nehrke, Hulicka, \& Morganti, 1984; Wagner, Lorion, \& Shipley, 1983) or have developed measures of it
(Darling-Fisher \& Leidy, 1988; Viney \& Tych, 1985). Since our study was designed to study a range of issues in a classic longitudinal study, we sought a measure that allowed for self-ratings, which had been used in more than one study, and which reported acceptable reliability and validity. In choosing a measure developed by Ryff and Heincke (1983) we adopt for further empirical investigation their definition of EI as "adapting to the triumphs and disappointments of being and to viewing one's past life as inevitable, appropriate, and meaningful" (p. 808).

At the outset, we must acknowledge that some investigators have argued against the utility of EI as a valid descriptor of the experiences of older people. Clayton (1975) contended that most individuals level off at earlier stages and thus fail to attain integrity with its accompanying virtue of wisdom. She concluded that Erikson's articulation of the tasks that we face in later life is insufficient, a criticism that we have heard about other developmental models (e.g., Kohlberg, 1981; Loevinger, 1976; Maslow, 1954). In all of these stage theories, it is said that most people level off somewhere just slightly above the middle.

Another critical aspect of its attainability concerns the context of aging and the physical health of its incumbents. Ego integrity is likely to be hindered by declining health. "Evidence from gerontological research suggests that physical morbidity and disability in old age are among the most important causes for decline in other functional domains such as social and psychological functioning" (Borchelt, Gilberg, Horgas, \& Geiselmann, 1999, p. 403). Some would argue that EI may only be realized by the well.

One final challenge to the validity of psychological stage-theory research in general and to the understanding of EI in particular is the extent to which it reflects a middle class bias (for a general discussion of these issues, see McAdams et al., 1993), and is more prevalent among the well-educated (see also Cantor, 2001; Fiske \& Chiriboga, 1990). Few studies have examined the relationship between educational attainment and EI.

Despite these challenges, a few consistent findings emerge from research that has been done to illuminate various aspects of EI. First, there is not strong support for the view that EI increases with age (Hannah et al., 1996; Ryff \& Heincke, 1983; Tesch, 1985; Whitbourne et al., 1992), although this may have to do with the fact that the age ranges in most of these studies are rather narrow. Ryff and Heincke (1983), however, found that all age groups perceive people in later life as more likely to manifest 
the characteristics of EI than do people at younger ages and stages. So, even if age is not typically correlated with EI (for an exception see DarlingFisher \& Leidy, 1988), there is a perception that it is. Most importantly, Erikson (1982) said that EI was a challenge of the aged-that wisdom only comes in later life (see Wink \& Helson, 1997 for a discussion of wisdom).

Second, while it is clear that aspects of each stage can be present at any age, EI is most often predicted by stages prior to it. In all the cross sectional studies surveyed here, scales assessing prior stages were significantly related to EI, with generativity being the most important predictor (Gruen, 1964; Hannah et al., 1996; Ryff \& Heincke, 1983). Longitudinal studies confirm the sequential nature of the theory up to the stage of Generativity (see for example, Stewart, Osborne, \& Helson, 2001; Vaillant, 1993; Vaillant \& Milofsky, 1980). These findings provide some support for the validity of the Erikson's theory as a matrix of evolving maturities, all of which require longitudinal data for confirmation, especially with respect to the place of EI in the sequence.

Third, the question of whether EI has relevance to women's lives has also been tested. So far, none of these studies has found significant sex differences (Darling-Fisher \& Leidy, 1988; Hannah et al., 1996; Ryff \& Heincke, 1983; Tesch, 1985). On the basis of these findings, it appears to have relevance to men's and women's lives.

In short, we need to know more about EI, both the concept itself and a popular measure of it. Few predictors suggested by the theory have been tested with longitudinal data. We do not know whether, for example, identity development in early adulthood affects later life stages or whether low manifestations of EI predict despair in old age. We also know very little about the meaning and experience of EI in people's lives. What does it mean to manifest it? Its virtue is supposedly wisdom, but how does it affect our daily lives? How does it relate to other psychological wellbeing indicators?

\section{Questions for the Current Study}

Building on previous work, we examined EI in our longitudinal sample of relatively healthy high functioning older women. With the caveat that our sample is small and the longitudinal nature of it limited by too much time between waves, we asked the following questions in the hope that our an- swers provide inspiration for further research of this type:

(1) Do ratings of prior stages predict EI? We examined the relationship between identity formation and educational attainment, assessed in 1951, and generativity in 1996. Because of the relevance of health to psychological development, we also included the women's own health assessment in the model. We then examined how these variables and generativity are related to EI assessed in 1996. Finally, we estimated the relationship between EI and despair, as would be predicted by Eriksonian theory.

(2) How does EI (inner life) relate to a set of quality of life issues (outer life) for the women of this study, e.g., their perspectives on helping/being helped, their willingness to participate in volunteer activities, marital satisfaction, and relationships with their midlife offspring.

(3) Is EI associated with better psychological health-positive aspects such as self acceptance, autonomy, mastery, purpose in life, growth, relationships with others, and/or negative aspects such as self-deprecation, tiredness, hostility, and confusion?

\section{METHOD}

\section{Participants}

The sample for this study is a group of White mothers of different social classes and ethnicities who participated in a study conducted by Sears, Maccoby, and Levin (1951), Patterns of Child Rearing. The original study included 379 children, ages 56 , and their mothers. The focus of the original study was to investigate the implications of the mothers' child-rearing behaviors for their children's short and longer-term development. A book, Patterns of Child Rearing, written by the original investigators (1957), was seen as a significant contribution to the field and is still cited today. The mothers (gl) from the original study are now over 70; their children (g2) are now in their early 50s. Several important followup studies of g2 have been conducted (Edwards, 1968; McClelland, 1978; McClelland \& Franz, 1988). In 1996, we recontacted the mothers of the original sample for the first time since the 1951 study. Despite an intensive search with $\mathrm{CD}$ ROM phone books, 
and other methods, we located less than one-half the original sample. This should not be surprising given the length of time between contacts, 1951-1996, and the reality that many of the mothers of the original sample are presumed dead.

Of the 154 mothers that we could locate, 50 were deceased; 9 were too ill to participate, and 17 declined. Of the mothers that we could locate, however, our sample includes 78 mothers, which is $82 \%$ of the women from the original study we could locate who were healthy enough to participate. Comparisons between the 1996 respondents and those from the 1951 sample we could not locate revealed no significant differences with respect to family income, social class, age, or number of children in the family; the 1996 respondents did, however, report higher levels of education ( $M=4.11$ and 3.55 , respectively, $p<.05$ ).

Most of the mothers were living in their own homes; only 1 mother was institutionalized. Fortyfour percent of the mothers were widowed; $47 \%$ were still living with husbands. They ranged in age from 70 to 91 (Mean age $=78$ ) and represented a range of social class; the original sample was selected to get both working and middle class participants. Approximately two-thirds of the mothers were from the 1951 middle class group. Still, $37 \%$ of our sample completed high school only (3\% did not complete high school); $31 \%$ had some college experience, but did not graduate; $29 \%$ completed college and beyond. These mothers contributed voluminous information via a questionnaire, which was sent to them by mail, and a 1-2 $\mathrm{hr}$ inperson interview in their homes, both of which we have used for these analyses.

Embedded in our questionnaire were detailed demographics, numerous measures including psychological well-being, health habits, beliefs, childrearing practices, and a host of other measures. For these analyses, we have drawn from their self-ratings of EI (Ryff \& Heincke, 1983), psychological wellbeing indicators (POMS; Ryff, 1989), the Loyola Generativity Scale [LGS] (McAdams, 1992), along with assessments of their psychological maturity assessed by the 1951 interviewing team. We have also considered certain demographic information such as age, educational attainment, and marital status.

The interview was conducted in the mother's home at her convenience and included questions about volunteer activities, her views of marriage and child rearing, her relationship with her adult children, especially the "study child" from the original study
(Sears, Maccoby, \& Levin, 1951), and the telling of the mother's "life story" (McAdams, 1993) during which the participant was asked to think of her life as if it were a book, divided into 5-6 chapters. She was asked to talk about themes of each chapter and to give this book a title. Interviews were conducted by trained interviewers all of whom were females in their late 40s. The interviews were tape recorded and transcribed with the mothers' permission.

\section{Measures}

Identity 1951 (Sears, Maccoby, \& Levin, 1957)

The 1951 interviewers were trained to assess the mother's sense of self after a 1-2 hr interview inquiring about many aspects of their lives, especially their views of the mother's role, child-rearing practices, feelings about giving up their jobs, and balancing their needs with the needs of the family. The original study was conducted some years before Erikson's notion of identity formation became a household word, but the authors coded a concept that seems remarkably like Erikson's notion of identity: a coherent sense of self as an entity including sameness, traits, role commitment, preferences, values, and confirmations (see Stewart, Franz, \& Layton, 1988). The interviewer's assessment included the following considerations:

\footnotetext{
This scale measures the [interviewers' assessment of] mother's sense of self. Does she feel she lives up to her own ideal values, with respect to achievement and temperament? Does she think she is bright, can get along with people, is a good mother? Expresses confidence, self-satisfaction as a person and mother. Compares self favorably with others. Amount of self-deprecation, amount of self-praise (codebook, p. 76).
}

We have used these ratings to represent the mother's level of identity development in 1951 as conceived by Erikson (1950).

\section{Ego Integrity (Ryff \& Heincke, 1983)}

Based upon Erikson's psychosocial stage theory of development, the 16-item Ryff measure included such statements as: "My life has been fulfilling, and I am not frightened by the thought of death"; "I wish my life were just beginning so I could avoid many of the mistakes I made earlier in my life" (reverse coded); and "All in all, I am comfortable 
with the choices I made regarding my life's work." Participants were asked to rate themselves using a 4-point Likert-type Scale ranging from 1: strongly disagree to 4: strongly agree. The internal consistency (Cronbach's $\alpha$ ) coefficient for the scale was .83 (similar to Ryff \& Heincke's .80). Ryff and Heincke also reported test-retest coefficients for the scale over a 6-week period as .85 .

\section{Loyola Generativity Scale [LGS] (McAdams \&} de St. Aubin, 1992)

Also derived from Eriksonian theory, the LGS is a 20-item scale designed to assess "generative concern," which, according to McAdams and de St. Aubin, includes both an inner desire and a cultural demand to participate in establishing and guiding the next generation. The internal consistency (Cronbach's $\alpha$ ) coefficient for the scale was 83 (identical to the authors' report of .83). The authors also report acceptable retest reliability, and both convergent and discriminant validity. McAdams and de St. Aubin reported strong positive associations with reports of so-called generative behaviors, such as "taught somebody a skill, provided constructive criticism about somebody's performance," "performance of community service."

\section{Profile of Mood States [POMS-BI]}

(Lorr \& McNair, 1988)

The POMS-BI, a recent edition of a test of mood states that has been evolving since 1971 (McNair, Lorr, \& Doppleman, 1971), was constructed to measure six bipolar subjective mood states. The six mood states include: composed-anxious; agreeable-hostile; confident-unsure; energetic-tired; clearheadedconfused; and elated-depressed. Over many years of research the POMS scales have demonstrated considerable reliability and validity (Lorr \& McNair, 1988). For purposes of this research, the six items associated with the depression scale, operationalized as despair, were used as the predicted outcome of low EI. Participants in the study were asked to rate themselves using a 4-point scale (4: much like this much to 1: much unlike this) on the following mood states: sad, dejected, lonely, downhearted, discouraged, and gloomy. The POMS-BI scales are believed to measure "a mood state that is more transient than a personality trait and yet more lasting than a momentary mood state produced by a short event like watching a film" (Weckowicz, 1978). The depression scale is not to be confused with clinical depression.

\section{Health Variables}

Study participants were given a list of health problems including cataracts, arthritis, high blood pressure, osteoporosis, high cholesterol, and heart problems. They were asked to check all that apply in terms of their own health. They were also asked to list any major illnesses that they might have had in the past. These were summed to create a health problems score.

Psychological Well-Being (Ryff, 1989; Ryff \& Essex, 1992)

To assess psychological well-being, participants completed a short version of Ryff's self-report inventory. It consists of six 3-item scales constructed to measure more positive dimensions of well-being such as autonomy (e.g., "I am not afraid to voice my opinions, even when they are in opposition to the opinions of most people"), environmental mastery ("I am quite good at managing the many responsibilities of my daily life"), personal growth ("For me, life has been a continuous process of learning, changing, and growth"), positive relations with others ("Most people see me as loving and affectionate"), purpose in life ("I feel good when I think of what I've done in the past and what I hope to do in the future"), and self-acceptance ("For the most part, I am proud of who I am and the life I lead"). Items were mixed into one continuous self-report instrument. Participants responded with a 6-point format ranging from 1: strongly disagree to 6: strongly agree. Responses to negatively scored items are reversed in the final scoring procedure so that high scores indicate high self-ratings on the dimension assessed. Internal consistency $(\alpha)$ coefficients for the scales ranged from .82 to .90 . (See Ryff, 1989, 1991 for more details about the measures.)

Additionally, more traditional psychological well-being scales from the POMS-BI such as uncertainty of self, hostility, tiredness, and anxiety were assessed in relation to EI.

\section{Interview Material (Content-Coded) Variables}

Several questions from the interview material were used to code different aspects of participants' 
quality of life as described below. The questions were asked in a relaxed open-ended way; respondents were allowed to elaborate on their answers and were probed as to the meaning of their responses. Coding was conducted by the second author who was blind to the respondents' EI score. When a subsample of 10 interviews, selected at random, were coded by a second rater, the inter-rater reliability, $\kappa$ coefficients, calculated separately for each variable, ranged from .69 to $1.0(M=.87)$. Variables discerned from these interviews are defined below.

\section{Volunteer Work}

Questions about volunteering included: In addition to helping others and being helped yourself, are there other outside commitments or activities that were important to you? Any volunteer work for example? Answers were coded as: volunteered actively in the past (1: never or infrequently; 2: frequently or daily). What about now? Are you involved in outside volunteer activities now?

\section{Marriage}

Questions about marriage included: On a scale of 1-10, with one being extremely unhappy and 10 being extremely happy, how would you rate your marriage when you were raising your children?; the same question was asked of their current marital satisfaction if married. This question was not openended, but participants were asked to elaborate on their choices (not coded).

\section{Relationships With Adult Children}

We asked the mothers if they thought they might have raised the study child differently from any of their other children (coded as yes/no). We also asked about their relationship with the study child in the following way: Many parents who have more than one child frequently say that while they love all their children equally, their relationship with each one is different. What is true about your situation? When you were raising your children, did you get along better with one of your other children than you did with [study child]? (coded as an overall impression-yes/no); What about now? Do you currently get along better with one of your other children than you do with [study child]? (coded as yes/no). We asked the mothers about their views of the study child: All parents have hopes and dreams for their children, which may or may not come true for a variety of reasons. Is there anything about [study child] of which you are especially proud? (coded as 1: very proud; 2 : not especially proud). Is there anything about him/her in which you might be a little disappointed? (coded as 1: some disappointment; 2: not at all disappointed).

From the questionnaire, we asked the mothers whether or not the family had fun together. We also asked a series of questions regarding the mother/study child relationship including: How close is your relationship with the study child now?; How well can you exchange ideas?; How similar are your opinions and values about life?; How well do you get along together now?; How well do you feel you understand the study child?; How well do you think the study child understands you? All of these questions were answered on a 6-point scale ranging from 1: not at all to 6: extremely. Finally we asked, compared to 10-15 years ago, would you say that your relationship has 1: gotten considerably worse/2: gotten somewhat worse/3: stayed about the same/4: improved somewhat/5: improved considerably.

\section{Helping/Being Helped}

In the course of the interview we asked the following questions: How do you feel about getting help when you need it these days (coded as 1: comfortable asking for help; 2: uncomfortable asking for help); Do you anticipate needing any kind of help in the future (coded as yes/no); Who do you think will provide that kind of help when you need it (friends or neighbors, spouse; children, other, all coded as yes/no); Will the study child help you (coded as yes/no); How do you think you will feel about receiving help from him/her (coded as 1: comfortable; 2 : reluctant, but willing; 3: unwilling).

\section{RESULTS}

Means, ranges, standard deviations, and intercorrelations of each of the measures are presented in Table I. From the total sample of 78 mothers, 70 responded to the section of the questionnaire asking them to rate themselves on the 16-item EI scale. Mean item-scores ranged from 2.25 to 3.81, $M=2.96$, standard deviation $=.38$. 
Table I. Intercorrelations Among Measures

\begin{tabular}{|c|c|c|c|c|c|c|c|}
\hline & Mean $(S D)$ & Years educated & Identity 1951 & Generativity & Health & Marital status & Despair \\
\hline Ego-integrity range $=2.25-3.81$ & $2.96(.38)$ & $.29 *$ & $.29^{*}$ & $.49^{* * *}$ & -0.2 & 0.02 & $-.33^{* *}$ \\
\hline Years educated range $=9-20$ & $13.91(2.22)$ & - & 0.08 & $.28^{*}$ & 0.11 & -0.07 & 0.02 \\
\hline Identity 1951 range $=1-3$ & $2.12(.82)$ & - & - & $.27^{*}$ & -0.06 & 0.01 & -0.07 \\
\hline Generativity range $=1.90-4.0$ & $2.83(.49)$ & - & - & - & -0.17 & 0.22 & $-.26^{*}$ \\
\hline Health range $=0-10$ & $3.27(2.25)$ & - & - & - & - & 0.04 & 0.13 \\
\hline Marital status & $.53(.50)$ & - & - & - & - & - & -0.19 \\
\hline Despair range $=3-2.5$ & $-.87(1.25)$ & - & - & - & - & - & - \\
\hline
\end{tabular}

${ }^{*} p<.05 ;{ }^{* *} p<.01 ;{ }^{* * *} p<.001$ (level required for Bonferroni correction).

Question 1: What are the predictors of EI in the general sample? Both theory and past research suggest that it would be related to previous developmental challenges: identity development, intimacy development, and generativity. Ego integrity, in turn, would predict despair. And since previous research presents conflicted findings with respect to health, we tested that relationship, along with education, about which little is known in relation to EI. Thus, we constructed a series of regression analyses to test the applicability of Erikson's theoretical model for this sample of mothers.

Figure 1 presents the results of these three regression models. For visual simplicity, we have presented the results as a path analysis framework; we do not intend to imply causality. For the first set of analyses, generativity was regressed on identity and level of educational attainment in 1951. The mothers' own health and marital status were included for their possible impact. As can be seen in Fig. 1, all of these variables significantly accounted for some of the variance in generativity in $1996\left(R^{2}=.23\right)$, with positive effects of both educational attainment and identity in 1951. Mothers' marital status significantly predicted generativity, so that those who still lived with/had spouses rated themselves higher in generativity than the other mothers, most of whom were widows. Mothers' health was not significantly related to generativity.

A second model was set up to test the relationship between generativity in 1996 and EI, also assessed in 1996. Again, both identity and educational attainment from the 1951 data, along with the physical health and marital status variables, were included in the model. Interestingly, and in keeping with Erikson's theory, generativity significantly predicted EI, the results of which can be seen in step 2 of the path in Fig. $1\left(R^{2}=.31\right)$. Neither identity in 1951 , nor educational attainment, nor mothers' health was significantly related to EI, once generativity was included in the model.

Finally, we constructed a third model to assess the extent to which EI related to depression. As can be seen in the third step represented in Fig. 1, the only significant predictor of despair is $\mathrm{EI}\left(R^{2}=.17\right)$.

The results of our three regression models provide clear support for the importance of the interconnections of at least three of Erikson's stages, and the psychological concomitant of EI. In our model, the more the mothers had a clear sense of self in

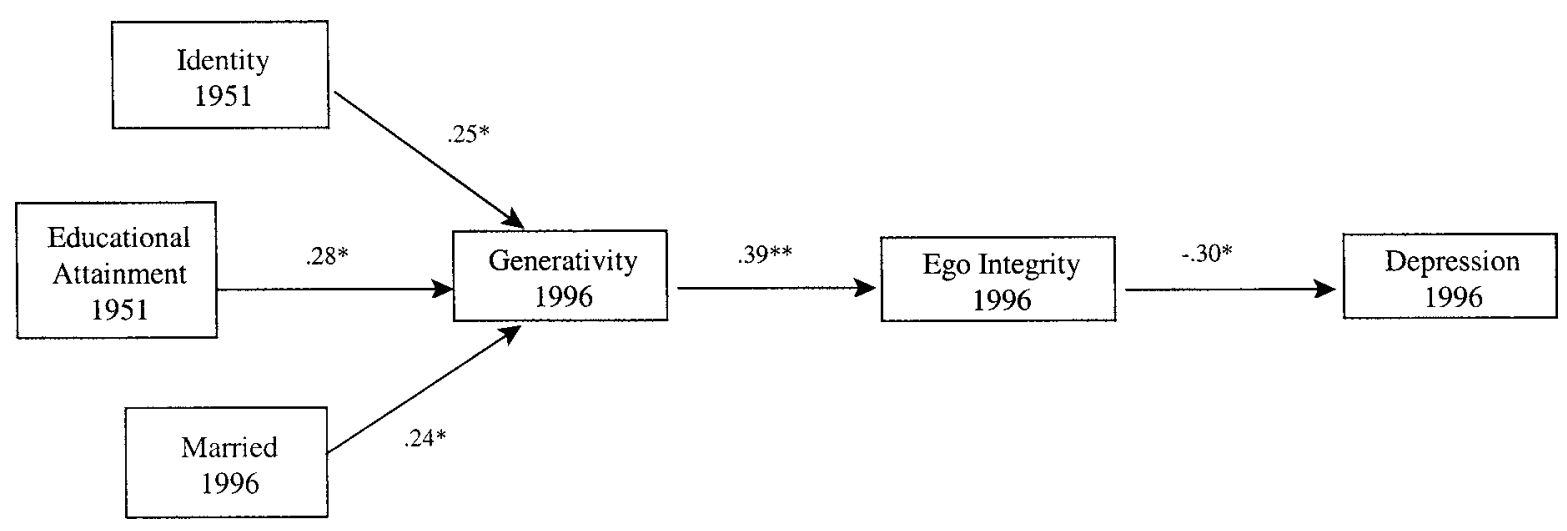

Fig. 1. A 3-model test of Eriksonian theory: 1951-1996. 
1951, the more likely they were to see themselves as generative in 1996. Moreover, the more the mothers considered themselves to be "generative" in 1996, the more likely they were to rate themselves as having EI and the less likely they were to be depressed in 1996.

Question 2: What are the defining characteristics of those who manifest high EI? To answer this question, we tested the relationship of EI to: helping others and accepting help from others; the level of volunteer work (both past and present); marital satisfaction (past and present); perspectives on the study child's childhood environment, and several aspects of their current relationships with adult children.

\section{Volunteer Work and Helping/Being Helped}

As can be seen in Table II, EI was significantly related to the amount of involvement in volunteer work, both in the past $(r=.35, p<.01)$ and in the present $(r=.43, p<.001)$. In fact the strongest relationship to $\mathrm{EI}$ in this category is current volunteer levels. In regard to receiving help, EI was not associated with "feeling okay about asking for help" in the present (the mothers were equally uncomfortable with the notion that they might have to ask for help), but was related to a feeling of comfort about receiving help when they really need it, both now, $(r=.31$, $p<.05)$ and in the future $(r=.27, p<.05)$. Two responses illustrate the reactions of low EI mothers: (1) "I don't know. Just if I'm going to die, I want to die right away. I don't want to be a burden to

Table II. Ego Integrity in Relation to Helping/Being Helped

\begin{tabular}{|c|c|c|c|c|c|c|c|c|c|}
\hline & EI & A & $\mathrm{R}$ & $\mathrm{F}$ & V1 & $\mathrm{V} 2$ & WSR & CSR & FSR \\
\hline EI & & .14 & $.31 *$ & $.27^{*}$ & $.35^{* *}$ & $.43^{* * *}$ & .03 & .24 & .05 \\
\hline A & & & $.66^{* * *}$ & $.35^{* *}$ & $.27^{*}$ & $.34^{* *}$ & .00 & .03 & .01 \\
\hline $\mathrm{R}$ & & & & $.49^{* * *}$ & $.29^{*}$ & $.41^{* * *}$ & .16 & .06 & .21 \\
\hline $\mathrm{F}$ & & & & & .18 & $.35^{* *}$ & .17 & .27 & .18 \\
\hline V1 & & & & & & $.45^{* * *}$ & .08 & $.40^{* *}$ & .17 \\
\hline V2 & & & & & & & .10 & .28 & .18 \\
\hline WSR & & & & & & & & $.52^{* * *}$ & $.52^{* * * *}$ \\
\hline CSR & & & & & & & & & $.40^{* *}$ \\
\hline
\end{tabular}

Note. EI: Ego Integrity Score; A: It is ok to ask for help (1: no/2: yes); R: It is ok to receive help; F: It will be ok to receive help in the future; V1: number of hours of volunteering/week, 1951; V2: number of hours of volunteering/week, 1996; WSR: work social responsibility score; CSR: community social responsibility score; FSR: family social responsibility score.

${ }^{*} p<.05 .{ }^{* *} p<.01 .{ }^{* * *} p<.001$ (level required for significance with Bonferroni correction). anybody. I never have been, and I don't want to start now. I don't know what help I'll be needing. I always say to Maureen (fictitious name of study child), 'If that happens to me, shoot me.'" (2) "Well, I figure that I already have it planned that I'm going to drop dead so that I won't need any help. I just planned it that way, so I don't think I'll need any help." On the other hand, two examples of response from the high EI mothers revealed that these mothers were more planful and more sanguine about accepting help if the need arose: (1) "Well, I have a wonderful support system now. I've been very lucky, and that's whyAnd I am willing to use it. I should put it that way because I have friends who have all the same things accessible to them and do not use it." (2) "It wouldn't bother me to ask them [her four children] for help. If they said no, I'd say, well, thank you very much; try the next one; just move along the line."

\section{Marriage}

Ego integrity was significantly related to marital satisfaction. Most of the mothers reported that marriage now is more satisfying than it was when they were raising their children (1951, $M=7.85 ; 1996$, $M=8.52 ; t=2.91, p<.01)$. Ego integrity, assessed in 1996, was associated with higher satisfaction at both points in time (1951, $r=.34, p .<.01 ; 1996, r=$ $.48, p<.001)$. Since our data did not include a scale of intimacy development, the stage in Eriksonian theory between identity and generativity, we speculate that marital satisfaction indicates some measure of achievement in this stage, missing from our model.

\section{Relationship With Adult Children}

As can be seen in Table III EI was not implicated in the tendency to say that one should raise different children in the family in different ways nor in the tendency to say that they liked one child better than another (Table IV). EI was significantly associated both with being proud of the study child $(r=.39, p<.001)$, and with being disappointed in some respects $(r=-.24, p<.05)$. Ego integrity was also significantly related to the extent the mother reported that the family had fun together $(r=.34$, $p<.01$ ), but not in the extent to which the family expressed a lot of love $(r=.18, n s)$.

Most importantly, mothers' ratings of different aspects of their relationship with the study child 
Table III. Ego Integrity in Relation to Past Relationships With Study Child

\begin{tabular}{|c|c|c|c|c|c|c|c|c|}
\hline & EI & DIF & L1 & L2 & PRD & DIS & FUN & LVE \\
\hline EI & & .10 & -.02 & -.09 & $.39^{* * *}$ & $-.24^{*}$ & $.34^{* *}$ & .18 \\
\hline DIF & & & .19 & -.01 & .15 & $-.23^{*}$ & .00 & .01 \\
\hline L1 & & & & .15 & -.01 & -.03 & .12 & .21 \\
\hline L2 & & & & & -.14 & .09 & -.22 & .01 \\
\hline PRD & & & & & & $-.33^{* *}$ & $.29^{*}$ & .16 \\
\hline DIS & & & & & & & -.08 & -.17 \\
\hline FUN & & & & & & & & $.53^{* * *}$ \\
\hline
\end{tabular}

Note. EI: total ego integrity score; DIF: Did you raise (study child) any differently than you did your other children (1: no/2: yes); L1: In the past, did you like one of your children better than the others; L2: In the present, do you like one of your adult children better than the others; PRD: Are you especially proud of (study child); DIS: Are there ways you are disappointed in (study child); FUN: score, to what extent did the family have fun together when you were raising (study child); LVE: score, to what extent did the family have fun when you were raising (study child).

${ }^{*} p<.05$. ${ }^{* *} p<.01$. ${ }^{* * *} p<.001$ (level required for significance with Bonferroni correction).

revealed a pattern of significant relationships with EI (see Table V). EI was related to mothers' assessment of how close they currently are with their midlife offspring $(r=.27, p<.05)$, with their ability to exchange ideas with them $(r=.33, p<.01)$, and with how well they get along now $(r=.31, p<.05)$. EI was not related to the mothers' perceptions of the degree to which there is understanding between mother and child, or the extent to which the relationship has improved in the last decade.

Question 3: Does EI predict better psychological health? As can be seen in Table V, EI is highly correlated with several indices of psychological well-being.

Table IV. Ego Integrity in Relation to Relationships With Adult Study Child

\begin{tabular}{llllllll}
\hline & EI & CLS & COM & LKE & MU & CU & BTR \\
\hline EI & & $.27^{*}$ & $.33^{*}$ & $.31^{*}$ & .23 & $.24^{*}$ & .01 \\
CLS & & & $.77^{* * *}$ & $.81^{* * *}$ & $.63^{* * *}$ & $.63^{* * *}$ & $.27^{*}$ \\
COM & & & & $.79^{* * *}$ & $.56^{* * *}$ & $.65^{* * *}$ & .27 \\
LKE & & & & & $.53^{* * *}$ & $.62^{* * *}$ & $.35^{* *}$ \\
MU & & & & & & $.74^{* * *}$ & .21 \\
CU & & & & & & $.24^{*}$ \\
\hline
\end{tabular}

Note. EI: total ego integrity score; CLS, rating (1-5) of "How close do you feel now to (study child)"; COM, rating of "How well do you communicate these days with (study child)"; LKE, rating of "How well do you and your study child get along these days"; MU: rating of "How well do you understand your study child"; CU: rating of "How well does the study child understand you"; BTR: rating of "To what extent has your relationship with your study child improved in the last 10 years or so."

${ }^{*} p<.05 .{ }^{* *} p<.01 .{ }^{* * *} p<.001$ (level required for significance with Bonferroni correction).
Table V. Ego Integrity in Relation to Psychological Well-being (Ryff, 1989)

\begin{tabular}{|c|c|c|c|c|c|c|c|}
\hline & EI & SA & AUT & MA & PUR & GW & OT \\
\hline EI & & $.67^{* * *}$ & $.25^{*}$ & $.45^{\text {*** }}$ & .16 & $.41^{* * *}$ & $.33^{* *}$ \\
\hline SA & & & $.30^{*}$ & $.43^{* * *}$ & .15 & $.39^{* * *}$ & $.33^{* *}$ \\
\hline AUT & & & & $.33^{* *}$ & $.30^{*}$ & $.41^{* * *}$ & $.33^{* *}$ \\
\hline MA & & & & & .02 & $.32^{* *}$ & $.33^{* *}$ \\
\hline PUR & & & & & & $.38^{* * *}$ & .22 \\
\hline GW & & & & & & & $.39^{* * *}$ \\
\hline
\end{tabular}

Note. EI: total ego integrity score; SA, self-acceptance; AUT, autonomy; MA, mastery; PUR, purpose in life; GW, growth; OT, positive relations with others.

${ }^{*} p<.05 .{ }^{* *} p<.01 .{ }^{* * *} p<.001$ (level required for significance with Bonferroni correction).

The strongest correlation is with self-acceptance $(r=$ $.67, p<.001)$, followed by environmental mastery $(r=.45, p<.001)$ and growth $(r=.41, p<.001)$. It was also significantly correlated with positive relations with others $(r=.33, p<.01)$, but not with purpose in life. In general, high EI mothers report psychological well-being, at least as assessed by the Ryff (1989) measure. Table V also reveals the extent to which the well-being scales are correlated with each other. Ryff (1989), while acknowledging the intercorrelations, makes the case that they "represent different facets of positive psychological functioning" (p. 1074).

In terms of more traditional measures of psychological well-being, the picture changes slightly. EI is negatively related to depression. It is not, however, significantly correlated with uncertainty of self, hostility, confusion, tiredness, or anxiety.

\section{DISCUSSION}

Erik Erikson suggested that maturity in later life was represented by a rather ill-defined concept which he labeled ego integrity. This study adds to growing evidence that EI can be operationalized and studied, and is associated with many positive concomitants. Our findings indicate that EI, as assessed by the Ryff and Heincke (1983) measure, is highly related to helping behaviors, expectations of support in times of need, the quality of relationships, and some aspects of psychological wellbeing. Indeed, the results suggest that Erikson's stage model of development is not one of those that has an unattainable highest level. His notion that one must resolve prior developmental challenges such as identity before EI can be attained seems to have 
merit as well. Identity, assessed in 1951, was a significant predictor of generativity assessed in 1996, which in turn predicted EI (albeit assessed concurrently). Integrity then significantly predicted despair, again, as the theoretical model would suggest. Education predicted identity development but self-rated health had no bearing on the relationships estimated here. These data, with acknowledged limitations, provide some support for Erikson's model of development with respect to adulthood and aging.

In order to clarify further the meaning of EI, it is interesting to consider variables that were not significantly related to it. While EI was associated with almost every element of the Ryff (1989) wellbeing scales, it was only related to the depression scale of the more traditional measure of mood states. In terms of psychological well-being, EI appeared to be most significantly linked to (from the Ryff, 1989 measure) self-acceptance (feeling comfortable with who I am), which must be differentiated from (the POMS measure) self-confidence (feeling capable and efficacious), to which it is not related. These findings suggest that, except for self-acceptance, using psychological well-being measures as proxies of EI is unwarranted.

Our findings, however, must be considered against the backdrop of these mothers' lived experiences. They grew up in a particular era which had a significant impact on their development (see for example Stewart \& Healy, 1989). To be a housewife and mother was the main legitimate social and economic space for them and the way to obtain adult status; to remain single or to pursue a profession was considered deviant for White women during this era (Breines, 1992). All of the women in this study were married women with at least one child. Most of these women gave up their work lives at the time of their marriage, and all of them had done so by the time children started to arrive.

In the context of such pressures, our finding of the importance of identity development assessed in 1951 for later developmental challenges in these women's lives cannot be understated. There has been much discussion of the ways in which relationships/connectedness are more central in women's development than are aspects of selfdefinition/autonomy (see for example Franz \& White, 1985). In the lives of these very traditional women, we expected relationships to be central, as indeed they were in many respects. The data suggest however, that women who have a clear sense of themselves in young adulthood, and who find avenues for expressing that self and identity, are able to meet later challenges (crises) more adroitly. Identity was defined as, among other things, "living up to her own ideal values with respect to achievement and temperament." Interestingly, the mothers in our sample who were rated as having more of these important aspects of self-definition reported having better marriages, and expressed greater generativity later on. It would appear that having a strong sense of self in early adulthood enhanced connections with others.

The aspect of generativity that involves parenting and guiding the next generation also bears comment. As Breines (1992) has pointed out, being a mother was almost a generational requirement for this group of women. It was interesting to note that the married women reported higher generativity than did the widowed or single women. Perhaps generativity declines with losses of intimacy, another major component of Erikson's stage theory, located between identity and generativity (but missing from our model). Most importantly, generativity appears to be enhanced by a strong sense of self (identity), and is itself the most important predictor of EI for this sample. While Eriksonian theory would predict that EI is preceded by generative concern, and other studies have confirmed its importance for EI (Hannah et al., 1996; Tesch, 1985), it is unknown whether our findings would be replicated in a less healthy sample, more diverse samples, in older women (or men) who never married or had children, nor in later generations.

Having demonstrated the efficacy of the Eriksonian model using these longitudinal data (two waves spanning 45 years), we asked what it meant in terms of real-life consequences to manifest high EI. Of course, our sample for these results was small and limited in terms of race and class, and in terms of having only two data points, but our results suggest that, for these women, EI is associated with several positive outcomes. Mothers with high EI also reported satisfying marriages, and close relationships with adult children. They were also more likely to report being proud of their adult children and getting along well with them as well. Most importantly, high EI mothers were more likely to feel safe in the assumption that someone, a child or several of their children, would provide support for them should they become "dependent," a point that requires some discussion.

Most of the mothers in this study reported discomfort with the notion that they might have to ask 
for help from others in the future. It was only when pressed, "Well, what if you really needed help (could not get by without it), who do you think would help you?" that the mothers were willing to specify what they would do. Past research suggests providing care for elderly relatives during these women's early lives may sensitize them to the hardship involved in such caregiving and may induce an unwillingness to articulate their needs for such care themselves (Hareven \& Adams, 1994; Post, 1990; Roberts, 1992).

Also, as we have seen, these mothers and their children arrive at this transition with decades of history - which can have a major impact on caregiving outcomes (Walker, Pratt, \& Eddy, 1995). Suitor, Pillemer, Keeton, and Robinson (1995) have shown that troubled relationships can lead to unwillingness to provide care for family members (see also Hamon \& Blieszner, 1990). The low EI mothers, who felt that their relationships were not congenial, were very uncertain of their future care even when pressed to think about it. Given the vulnerability to illness and the potential need for care in later life, we see these concomitants of high and low EI as particularly important.

Our results also support Erikson's contention that EI is the manifestation of psychological health in later life, at least those associated with the Ryff (1989) scales. The extent to which EI increased was significantly associated with greater self-acceptance, environmental mastery, personal growth, and relations with others. These mothers with high EI were functioning well-accepting life for what it is, still striving for self-improvement and manifesting interpersonal sensitivity.

Overall, our analyses of the relationships among EI and the concerns assessed here suggest that high EI is less an achievement than a way of operating in the world. Erikson (1982) said:

If we consider integrity merely a noble ideal to be embroidered on a banner and raised high in appropriate situations, we would be doing it a grave injustice. Integrity has the function of promoting contact with the world, with things, and, above all, with people. It is a tactile and tangible way to live, not an intangible, virtuous goal to seek after and achieve (p. 8).

Clearly, these mothers who are high in EI manifest active engagement in the world around them, enjoying positive relationships, expecting to care and be cared for, and manifesting several elements of psychological well-being.
EI, as a conception of maturity, allows for positive adaptation while acknowledging the despair that can seep into later life, and provides information about adaptation that includes but may go beyond psychological well-being or adjustment. If identity is self-definition with an eye toward the future, EI seems to be self-definition with an eye on the past; this aspect may in fact explain why it was not correlated with purpose in life. Even though Erikson (1963) boasts of wisdom as the virtue associated with EI, our findings suggest that it is associated with a host of more down-to-earth benefits as well.

\section{ACKNOWLEDGMENTS}

Parts of this paper were presented at the American Psychological Association Annual Meeting, Boston, August 20-24, 1999. The authors gratefully acknowledge permission from the Murray Research Center and the screening committee for the original study (Sears, Maccoby, \& Levin, 1951, Patterns of Child Rearing), to conduct the follow-up study presented here, and financial support provided by the Radcliffe College President's fund. Janet Malley was the inspiration for the project and an invaluable collaborator in all phases of conducting the Patterns of Family Life study. Our interviewing team made it possible to acquire a large amount of data in a reasonable time frame. We also appreciate helpful comments on this manuscript from Annemette Sorensen, Brian Little, and Paul Wink, and help in preparing it from Evelyn Liberatore and Emiko Saito. Most importantly, we thank the women whose lives are documented here for their tremendous generosity in sharing their experiences with us.

\section{REFERENCES}

Baltes, P. B., \& Mayer, K. U. (1999). The Berlin aging study: Aging from 70 to 100. Cambridge, UK: Cambridge University Press.

Borchelt, M., Gilberg, R., Horgas, A. L., \& Geiselmann, B. (1999). On the significance of morbidity and disability in old age. In P. B. Baltes \& K. U. Mayer (Eds.), The Berlin aging study: Aging from 70 to 100 (pp. 403-429). Cambridge, UK: Cambridge University Press.

Breines, W. (1992). Young, White, and miserable: Growing up female in the fifties. Boston: Beacon.

Cantor, D. L. (2001). Sources of generativity in older women: A Life-span developmental perspective. Unpublished dissertation.

Clayton, V. (1975). Erikson's theory of human development as it applies to the aged: Wisdom as contradictive cognition. Human Development, 18(2), 119-128. 
Darling-Fisher, C. S., \& Leidy, N. K. (1988). Measuring Eriksonian development in the adult: The modified Erikson psychosocial stage inventory. Psychological Reports, 62, 747-754.

Edwards, C. (1968). Some developmental antecedents of psychopathology: Follow-up of patterns of child rearing.

Erikson, E. H. (1950). Childhood and society (1st ed.). New York: W.W. Norton.

Erikson, E. H. (1963). Childhood and society (2nd ed.). New York: W.W. Norton.

Erikson, E. H. (1982). The life cycle completed. New York: W.W. Norton.

Erikson, E. H., Erikson, J. M., \& Kivnick (1986). Vital involvement in old age. New York: W.W. Norton.

Fiske, M., \& Chiriboga, D. A. (1990). Change and continuity in adult life. San Francisco: Jossey-Bass.

Franz, C., \& White, K. (1985). Individuation and attachment in personality development. In A. J. Stewart \& B. Lykes (Eds.), Gender and personality. Durham, NC: Duke University Press.

Gruen, W. (1964). Adult personality: An empirical study of Erikson's theory of ego development. In B. L. Newugarten (Ed.), Personality in middle and late life. New York: Atherton.

Hamon, R. R., \& Blieszner, R. (1990). Filial responsibility expectations among adult child-older parent pairs. Journal of Gerontology, 45(3), 110-112.

Hannah, M. T., Domino, G., Figueredo, A. J., \& Hendrickson, R. (1996). The prediction of ego integrity in older persons. Educational and Psychological Measurement, 56(6), 930950.

Hareven, T. K., \& Adams, K. (1994). The generation in the middle: Cohort comparison in assistance to aging parents in an American community. In T. K. Hareven (Ed.), Aging and generational relations over the life course: $A$ historical and cross-cultural perspective. Berlin: Walter de Gruyter.

Kohlberg, L. (1981). Essays in moral development: Vol. I. The philosophy of moral development. New York: Harper \& Row.

Kotre, J. N. (1984). Outliving the self: Generativity and the interpretation of lives. Baltimore: Johns Hopkins University Press.

Loevinger, J. (1976). Ego development. San Francisco: JosseyBass.

Lorr, M., \& McNair, D. M. (1988). Profile of mood states manual (POMS-BI). San Deigo, CA: Educational and Industrial Testing Service.

MacDermid, S., Franz, C., \& De Reus, L. A. (1998). Adult character: Agency, communion, insight, and the expression of generativity in mid-life adults. In A. Colby, J. James, \& D. Hart (Eds.), Competence and character through life (pp. 203230). Chicago: University of Chicago Press.

Maslow, A. H. (1954). Motivation and personality. New York: Harper \& Row.

McAdams, D. P. (1993). The stories we live by: Personal myths and the making of the self. New York: William Morrow.

McAdams, D. P. (2000). Attachment, intimacy, and generativity. Psychological Inquiry, 11(2), 117-120.

McAdams, D. P., \& de St. Aubin, E. (1992). A theory of generativity and its assessment through self-report, behavioral acts, and narrative themes in autobiography. Journal of Personality and Social Psychology, 62, 1003-1015.

McAdams, D. P., de St. Aubin, E., \& Logan, R. L. (1993). Generativity among young, midlife, and older adults. Psychology \& Aging, 8(2), 221-230.

McClelland, D. C. (1978). Follow-up of patterns of child rearing.

McClelland, D. D., \& Franz, C. (1988). Life Patterns Project: 198788 follow-up of patterns of child rearing.

McNair, D. M., Lorr, M., \& Doppleman, L. F. (1971). Profile of mood states. San Diego, CA: Educational and Industrial Testing Service.
Nehrke, M. F., Bellucci, G., \& Gabriel, S. J. (1978). Death anxiety, locus of control, and life satisfaction in the elderly: Toward a definition of ego integrity. Omega, 8, 359368.

Nehrke, M. F., Hulicka, I. M., \& Morganti, J. D. (1984). Age differences in life satisfaction, locus of control, and self-concept. International Journal of Aging and Human Development, 11(1), $25-33$.

Peterson, B. E., \& Duncan, L. E. (1999). Generative concern, political commitment, and charitable actions. Journal of Adult Development, 6(2), 105-118.

Peterson, B. E., \& Stewart, A. J. (1993). Generativity and social motives in young adults. Journal of Personality and Social Psychology, 65(1), 186-198.

Post, S. G. (1990). Women and elderly parents: Moral controversy in an aging society. Hypatia, 5(1), 83-89.

Roberts, P. (1992). I think of Ronald Reagan: Future selves in the present. International Journal of Aging and Human Development, 34(2), 91-107.

Ryff, C. D. (1989). Happiness is everything, or is it? Explorations on the meaning of psychological well-being. Journal of Personality and Social Psychology, 57(6), 10691081.

Ryff, C. D. (1991). Possible selves in adulthood and old age: A tale of shifting horizons. Psychology and Aging, 6(2), 286295.

Ryff, C. D., \& Essex, M. J. (1992). Psychological well-being in adulthood and old age: Descriptive markers and explanatory processes. In K. W. Schaie (Ed.), Annual Review of Gerontolgy and Geriatrics (Vol. 11, pp. 144-171). New York: Springer.

Ryff, C. D., \& Heincke, S. G. (1983). Subjective organization of personality in adulthood and aging. Journal of Personality and Social Psychology, 44(4), 807-816.

Sears, R., Maccoby, E., \& Levin, H. (1951). Patterns of child rearing.

Sears, R., Maccoby, E., \& Levin, H. (1957). Patterns of child rearing. Stanford, CA: Stanford University Press.

Slater, C. L. (2003). Generativity versus stagnation: An elaboration of Erikson's adult stage of human development. Journal of Adult Development, 10(1), 53-65.

Stewart, A. J., Franz, C., \& Layton, L. (1988). The changing self: Using personal documents to study lives. Journal of Personality, 56(1), 41-74.

Stewart, A. J., \& Healy, J. (1989). Linking individual development and social changes. American Psychologist, 44(1), 3042.

Stewart, A. J., Osborne, J. M., \& Helson, R. (2001). Middle aging in women: Patterns of personality change from the 30 s to the 50s. Journal of Adult Development, 8, 23-37.

Suitor, J. J., Pillemer, K., Keeton, S., \& Robinson, J. (1995). Aged parents and aging children: Determinants of relationship quality. In R. Blieszner \& V. H. Bedford (Eds.), Handbook of Aging and the Family (pp. 223-242). Westport, CT: Greenwood.

Tesch, S. A. (1985). Psychosocial development and subjective well-being in an age cross-section of adults. International Journal of Aging and Human Development, 21(2), 109_ 120.

Vaillant, G. E. (1993). The wisdom of the ego. Cambridge, MA: Harvard University Press.

Vaillant, G. E. (2002). Aging well: Surprising guideposts to a happier life from the land mark Harvard Study of Adult Development. Boston: Little, Brown.

Vaillant, G. E., \& Milofsky, E. M. (1980). The natural history of male psychological health, IX: Empirical evidence for Erikson's model of the life cycle. American Journal of Psychiatry, 137, 1348-1359. 
Viney, L. L., \& Tych, A. M. (1985). Content analysis scales measuring psychosocial maturity in the elderly. Journal of Personality Assessment, 49(3), 311-317.

Wagner, K. D., Lorion, R. P., \& Shipley, E. T. (1983). Insomnia and psychosocial crisis: Two studies of Erikson's developmental theory. Journal of Consulting and Clinical Psychology, 51, 595-603.

Walker, A. J., Pratt, C. C., \& Eddy, L. (1995). Informal caregiving to aging family members: A critical review. Family Relations, 44, 402-411.
Weckowicz, T. E. (1978). Profile of mood states. In O. Buros (Ed.), The eighth mental measurements yearbook. Highland Park, NJ: The Gryphon.

Whitbourne, S. K., Zuschlag, M. K., Elliot, L. B., \& Waterman, A. S. (1992). Psychosocial development in adulthood: A 22-year sequential study. Journal of Personality and Social Psychology, 63, 260-271.

Wink, P., \& Helson, R. (1997). Practical and transcendent wisdom: Their nature and some longitudinal findings. Journal of Adult Development, 4, 1-15. 